\title{
Effect of Gamma-Ray Irradiation on the Growth of Au Nano-Particles Embedded in the Germano-Silicate Glass Cladding of the Silica Glass Fiber and its Surface Plasmon Resonance Response
}

\author{
Seongmin Ju(i) and Won-Taek Han *(1) \\ School of Electrical Engineering and Computer Science, Gwangju Institute of Science and Technology, \\ Gwangju 61005, Korea; jusm@gist.ac.kr \\ * Correspondence: wthan@gist.ac.kr; Tel.: +82-62-715-2215
}

Received: 5 March 2019; Accepted: 6 April 2019; Published: 8 April 2019

\begin{abstract}
The effect of $\gamma$-ray irradiation on the surface plasmon resonance (SPR) sensing capability of refractive index $(\mathrm{n}=1.418-1.448)$ of the silica glass optical fiber comprised of germano-silicate glass cladding embedded with Au nano-particles (NPs) was investigated. As the $\gamma$-ray irradiation increased from $1 \mathrm{~h}$ to $3 \mathrm{~h}$ with the dose rate of $1190 \mathrm{~Gy} / \mathrm{h}$, the morphology of the Au NPs and the SPR spectrum were found to change. The average diameter of Au NPs increased with the aspect ratio from 1 to 2, and the nano-particles became grown to the clusters. The SPR band wavelength shifted towards a longer wavelength with the increase of total dose of $\gamma$-ray irradiation regardless of the corresponding refractive indices. The SPR sensitivities (wavelength/refractive index unit, $\mathrm{nm} / \mathrm{RIU}$ ) also increased from $407 \mathrm{~nm} /$ RIU to $3553 \mathrm{~nm} / \mathrm{RIU}, 1483 \mathrm{~nm} / \mathrm{RIU}$, and $2335 \mathrm{~nm} / \mathrm{RIU}$ after the $\gamma$-ray irradiation at a total dose of $1190 \mathrm{~Gy}, 2380 \mathrm{~Gy}$, and $3570 \mathrm{~Gy}$, respectively.
\end{abstract}

Keywords: $\gamma$-ray irradiation; surface plasmon resonance; fiber sensor; nano-particles; cladding embedded optical fiber

\section{Introduction}

Transparent host materials embedded with noble metal nano-particles (NPs) such as Au and Ag are of great interest due to their unique characteristics of surface plasmon resonance (SPR) arising from the excitation of electron density oscillations around metal NPs [1-9]. The localized SPR usually observed by confined colloidal, periodic, nano-systems gets resonantly excited when the wavelength of incident light is equal to the characteristic wavelength of metal NPs [10-13]. This comes from confined conduction electrons oscillating in resonance with the electromagnetic field. The localized SPR of metal nanostructures seems much more suitable for spectral tunability and strong enhancement of the local electric field [14]. Thus, the localized SPR has been widely used in the sensing of chemical, physical, and biological quantities based on the change of the refractive index [15-23].

The position and intensity of the SPR band depend on the size, shape, and inter-particle separation of the NPs and the dielectric property of the matrix surrounding the NPs $[3,4,7,24-33]$. The position of SPR peak is known to shift towards long or short wavelengths upon the change in NPs size. Therefore, various fabrication methods of metal NPs with different geometries such as nano-spheres, nano-rod, nano-shells, nano-tubes, nano-cubes, nano-wires, etc. have been proposed to increase the sensitivity and usability of the SPR sensors [7,24,26-30,32-38]. Among these NPs, for the strong absorption of incident light followed by field enhancement of the surface of Au NPs, spherical Au NPs are more favorable because of their isotropic structures which allow coupling to occur in every direction, rather than only in one direction of Au NPs $[39,40]$. However, even though spherical NPs have strong SPR 
absorption, there is a limit in terms of amplitude increase and spectral tunability in the visible-NIR region. Also, a single strong SPR spectral feature usually deviates when the eccentricity of the particles increases [41]. Because of these reasons, longitudinal SPR absorption by controlling the aspect ratio of $\mathrm{Au}$ NPs has attracted much attention for its large sensitivity and spectral tunability [42].

Various post-processing techniques of the irradiation by the pulsed laser, the charged ion, and the $\gamma$-ray have been investigated to control NPs with desired size and shape [13,43-50]. Our group has reported a heat treatment method to control the size of NPs in glass fiber [51,52]. Among such post-irradiation processing techniques, the high energy irradiation was proven to control effectively the size, shape, and spacing of the NPs by creating ion tracks resulting from Coulomb explosion and/or thermal spikes accompanying the excitations [53-56]. Due to the passage of a swift heavy ion, the particles grow and combine into clusters leading to chemical, physical, and optical changes [57].

Recent advances in the SPR application have led to the realization of the optical fibers incorporated with metal NPs and the fibers coated with metal thin layers [58-66]. In the SPR sensor based on the optical fiber, an evanescent wave is formed by the interface between the surface of the optical fiber and the metal NPs embedded or coated on the surface. The fiber-optic SPR sensor is an alternative to overcome the disadvantages of previous conventional prism-based SPR sensors because of its attractive advantages of simple and flexible design, compactness, and remote sensing capability for all-optical applications. Especially, the development of a fiber-optic localized SPR sensor based on noble metal NPs has attracted increasing attention, because it provides several advantages over the use of continuous metal thin films, such as the ease of fabrication, modification and control and the high sensitivity due to the increased surface area of metal/glass interface $[67,68]$. The fiber-optic localized SPR sensor for label-free biochemical sensors simply measures the change in absorption spectra by sweeping broadband light through NPs in the fiber [68,69]. Recently, we have reported the fiber-optic refractive index sensor using the novel optical fiber incorporated with Au NPs in the cladding [52,70]. In this paper, we report new results of the effect of $\gamma$-ray irradiation on the SPR sensing capability by inducing the morphological change in Au NPs embedded in the fiber.

\section{Experiments}

\subsection{Optical Fiber for Surface Plasmon Resonance Sensor}

The fabrication process of the germano-silicate optical fiber embedded with Au NPs in the cladding and the measurement of its SPR sensing property was described in detail in our previous work $[52,70,71]$. The Au NPs(cladding)-doped glass fiber coated with low refractive index polymer (SSCP Co., Ltd., Ansan-si, Kyunggi-do, South Korea, FIRON UVF PC-375, n = 1.3820 @ 852 nm) was designed to enable a light to propagate into the cladding, not into the core. Note that the refractive index of the cladding was larger than that of the core and the polymer coating. The refractive index difference between the cladding and the core $\left(\Delta \mathrm{n}_{\text {cladding-core }}\right)$ and that between the cladding and the coating $\left(\left(\Delta \mathrm{n}_{\text {cladding-coating }}\right)\right.$ were 0.0015 and 0.0764 , respectively. The cladding width and total diameter of the optical fiber were $2.6 \mu \mathrm{m}$ and $124.3 \mu \mathrm{m}$, respectively. Thus, surface plasmon waves are induced around Au NPs in the cladding of the fiber by a light wave traveling through the cladding.

The cladding width was designed and optimized by considering the launching efficiency of light and the subsequent SPR sensing efficiency. If the cladding containing Au NPs is large over the optimized width under the assumption that the concentration of Au NPs as well as size, shape, and inter-particle separation of the NPs is constant, the launching efficiency of light into the cladding of the fiber definitely increases, but the SPR sensing efficiency will not be affected much due to the increase of the distance from the fiber surface to the sensing objects. On the other hand, if the cladding is thin, the concentration of Au NPs per unit area increases, but less light goes through the cladding of the fiber and thus the SPR sensing efficiency will not be affected either. 


\subsection{Verification of Existence and Morphology of Au Nano-Particles}

To investigate the effect of $\gamma$-ray irradiation on change in morphology of Au NPs and the SPR sensing capability, the fabricated fiber was irradiated by $\gamma$-ray from a ${ }^{60} \mathrm{Co}$ radiation source (Nordion Inc., Ottawa, ON, Canada, MSD Nordion, pencil type/C-188 sealed) with the dose rate of $1190 \mathrm{~Gy} / \mathrm{h}$ for $1 \mathrm{~h}$ to $3 \mathrm{~h}$ at room temperature in air. The $\gamma$-ray doses were measured using the alanine pellet dosimeter and estimated by electron paramagnetic resonance analysis with BRUKER's e-scan alanine dosimetry system (Bruker Inc., Billerica, MA, USA). Then to confirm the formation and the change in size and distribution of Au NPs, the samples of the fibers with and without the $\gamma$-ray irradiation were examined by transmission electron microscopy (TEM; FEI Co., Hillsboro, OR, USA, Technai ${ }^{\mathrm{TM}}$ $\mathrm{G}^{2} \mathrm{~F} 30 \mathrm{~S}$-Twin $300 \mathrm{KeV}$ ), which were prepared after flaking the surface of the fiber in the longitudinal direction by the dual beam focused ion beam (FIB; FEI Co., Hillsboro, OR, USA, Helios NanoLab ${ }^{\mathrm{TM}}$ FIB 600). Optical absorption of the fibers was measured to verify again the existence of Au NPs by the cut-back method using the optical spectrum analyzer (OSA; Ando Electric Co., Ltd., Kanagawa Kawasaki-shi, Kanagawa-ken, Japan, AQ 6315B) and white light source (WLS; Ando Electric Co., Ltd., Kawasaki-shi, Kanagawa-ken, Japan AQ 4305). Note that the variation of the input light signal is eliminated because only the change in the length of the fiber is measured by the cut-back method.

\subsection{Surface Palsmon Resonance Measurement}

To characterize SPR sensing property, the change in optical absorption by the $\gamma$-ray irradiation was measured by putting small drops of the refractive index matching oil with various refractive indices $(\mathrm{n}=1.418-1.448$, Cargille Labs, Cedar Grove, NJ, USA) on the surface of the stripped portion $(3 \mathrm{~cm})$ of the $10 \mathrm{~cm}$ fiber (Figure 1). The coated polymer of the irradiated fiber was stripped off using acetone and the fiber was spliced with a commercial multi-mode fiber (diameters of core, cladding, coating were 105, 125, and $250 \mu \mathrm{m}$, respectively). The light was launched into the commercial multi-mode fiber with FC/PC-type connector for stable light supply and the resonance wavelength was measured by directly coupled to the OSA using a bare-fiber adapter without splicing with another fiber in order to minimize the signal distortion or intensity degradation at the other end of the fiber. Note that the change in optical absorption of the fiber without $\gamma$-ray irradiation was measured by using the fiber of $20 \mathrm{~cm}$ total length with the surface of the stripped portion $(3 \mathrm{~cm})$ according to the optimized fiber length for SPR sensor implementation derived from previous experimental results [70].

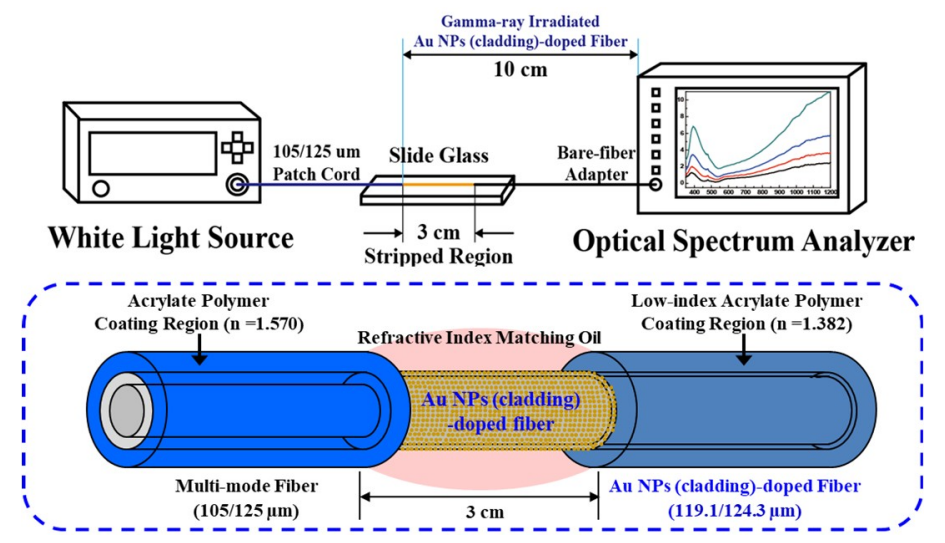

Figure 1. Schematic diagram of the SPR measurement set-up using the optical fiber incorporated with $\mathrm{Au}$ NPs in the cladding.

\section{Results}

TEM images and size distributions of Au NPs in the cladding of the fiber before and after the $\gamma$-ray irradiation are shown in Figure 2. The morphology of the Au NPs was dramatically changed with the increase of the $\gamma$-ray irradiation dose level from 0 Gy to $1190 \mathrm{~Gy}, 2380 \mathrm{~Gy}$, and $3570 \mathrm{~Gy}$. Before 
the $\gamma$-ray irradiation, the crystalline Au NPs were spherical and uniformly distributed with average diameter of $3.8 \mathrm{~nm}(2.5 \mathrm{~nm} \sim 5.2 \mathrm{~nm})$ with the aspect ratio of 1.00 . After irradiation, most of the Au NPs seemed to aggregate and became clusters. Under the total dose of $\gamma$-ray irradiation with $1190 \mathrm{~Gy}$, $2380 \mathrm{~Gy}$, and $3570 \mathrm{~Gy}$, the short axis lengths was $4.0 \mathrm{~nm}$ (size distribution: $2.3 \mathrm{~nm} \sim 5.8 \mathrm{~nm}$ ), $4.2 \mathrm{~nm}$ (size distribution: $2.0 \mathrm{~nm} \sim 6.8 \mathrm{~nm}$ ), and $4.5 \mathrm{~nm}$ (size distribution: $1.8 \mathrm{~nm} \sim 6.9 \mathrm{~nm}$ ), respectively, and the long axes lengths were $4.2 \mathrm{~nm}$ (size distribution: $2.3 \mathrm{~nm} \sim 9.6 \mathrm{~nm}$ ), $5.4 \mathrm{~nm}$ (size distribution: $2.0 \mathrm{~nm} \sim 12.7 \mathrm{~nm}$ ), and $9.0 \mathrm{~nm}$ (size distribution: $1.8 \mathrm{~nm} 20.7 \mathrm{~nm}$ ), respectively.
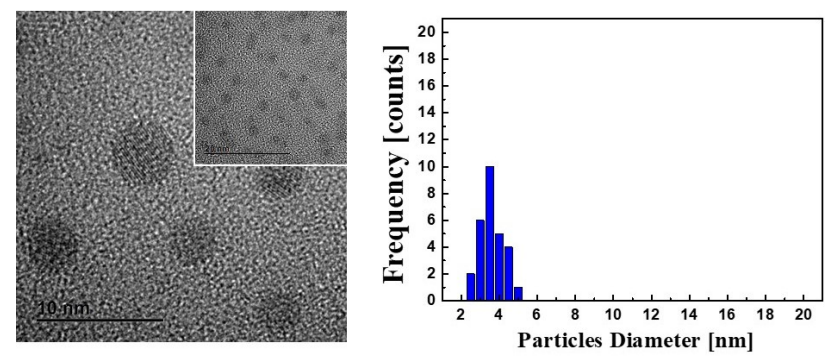

(a)
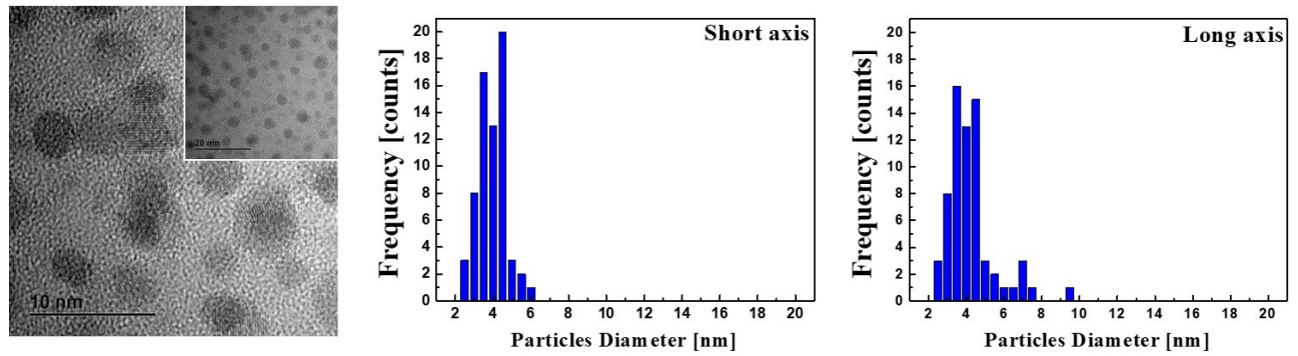

(b)
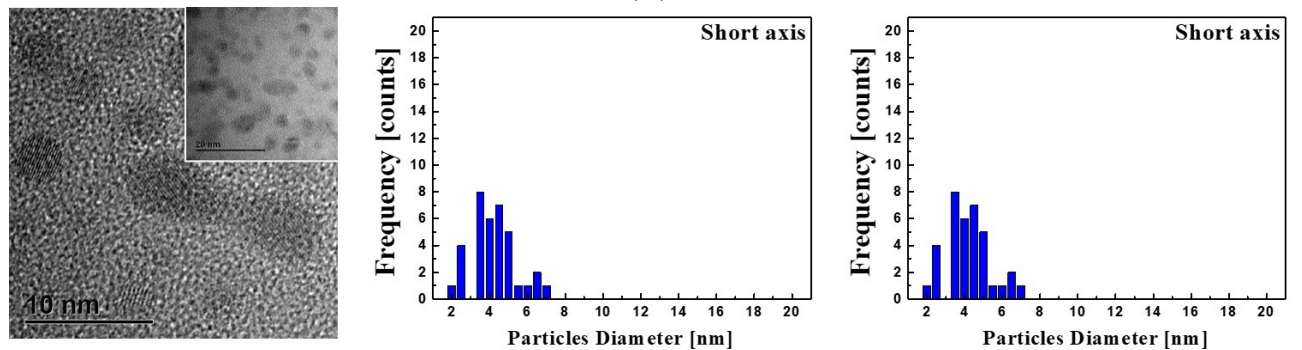

(c)
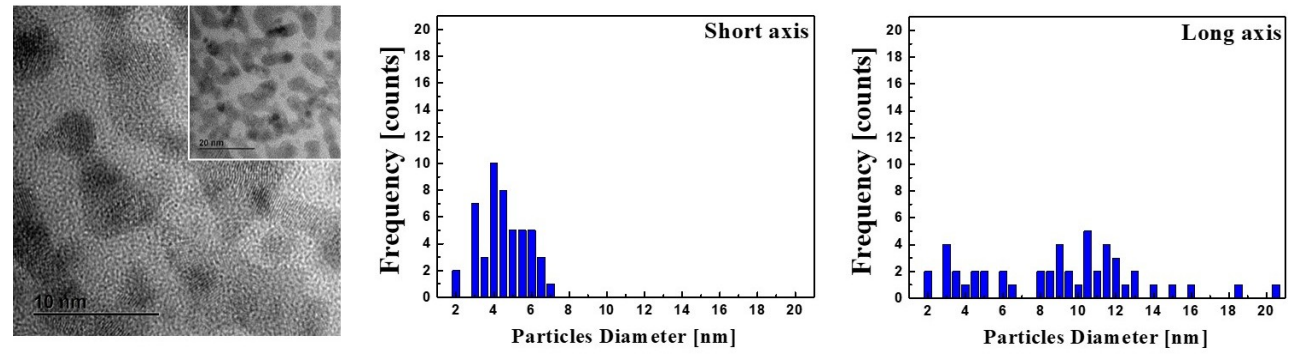

(d)

Figure 2. TEM images and size distribution of the major and minor axis lengths of the Au NPs incorporated in the cladding of the fiber (a) before and after the $\gamma$-ray irradiation at the total dose of (b) 1190 Gy, (c) $2380 \mathrm{~Gy}$, and (d) 3570 Gy.

To verify the existence of Au NPs in the fiber cladding again, optical absorption was measured by the cut-back method. Figure 3a compares the optical absorption spectra of the fibers before and after the $\gamma$-ray irradiation at the total dose of $1190 \mathrm{~Gy}, 2380 \mathrm{~Gy}$, and $3570 \mathrm{~Gy}$. Before irradiation, the absorption 
bands due to SPR were found to appear peaking at $392 \mathrm{~nm}$ (absorption coefficient $\alpha=0.088 \mathrm{~cm}^{-1}$ ) and $509 \mathrm{~nm}\left(\alpha=0.066 \mathrm{~cm}^{-1}\right)$, which depended on the particle size of Au NPs in the cladding of the fiber $[5,8,52,72]$. After the $\gamma$-ray irradiation, the intensity and the peak wavelength of the two SPR bands were found to change. While the second SPR band at a longer wavelength of $509 \mathrm{~nm}$ has clearly shown the increase of its intensity and wavelength shift, the first SPR band at $392 \mathrm{~nm}$ has not shown any significant increase of its intensity and wavelength shift. With the increase of $\gamma$-ray irradiation dose, the splitting of the SPR bands became more distinct [2,59-61]. The intensity of the second absorption band at $509 \mathrm{~nm}$ corresponding to the interparticle plasmon coupling of the aggregated Au NPs at the total dose of $1190 \mathrm{~Gy}$ increased from $\alpha=0.160 \mathrm{~cm}^{-1}$ to $\alpha=0.212 \mathrm{~cm}^{-1}$, and $\alpha=0.249 \mathrm{~cm}^{-1}$ at the total dose of 2380 Gy and 3570 Gy, respectively. Note that the absorption band around $392 \mathrm{~nm}$, which cannot be distinguished whether it is corresponding to spherical Au NPs or the radiation-induced defects by the $\gamma$-ray irradiation, at the total dose of 1190 Gy also increased from $\alpha=0.178 \mathrm{~cm}^{-1}$ to $\alpha=0.204 \mathrm{~cm}^{-1}$ and $\alpha=0.226 \mathrm{~cm}^{-1}$ with total doses of 2380 Gy and $3570 \mathrm{~Gy}$, respectively.

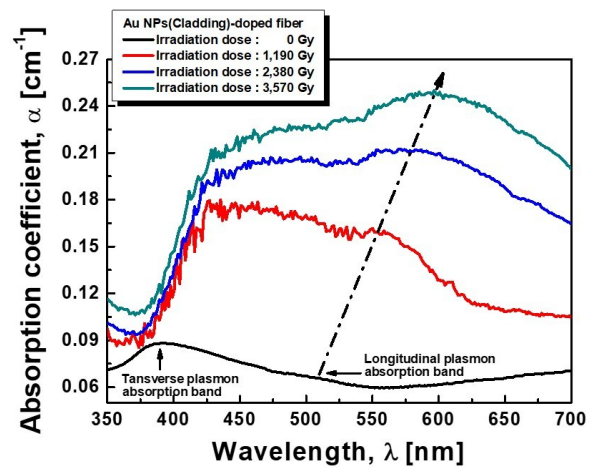

(a)

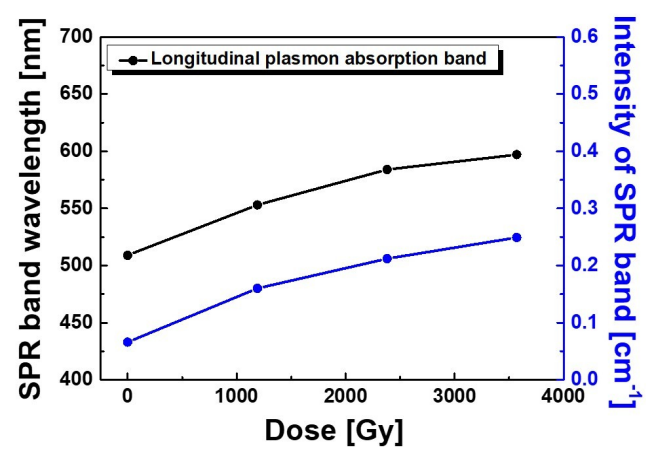

(b)

Figure 3. (a) Absorption spectra and (b) peak wavelength and intensity of the SPR band of the optical fiber incorporated with Au NPs before and after the $\gamma$-ray irradiation at the total dose of $1190 \mathrm{~Gy}$, $2380 \mathrm{~Gy}$, and $3570 \mathrm{~Gy}$.

Considering that the change of the refractive index and the residual stress of the fiber induced by the $\gamma$-ray irradiation may affect the transmission characteristics of the optical signal, the refractive index and the residual stress of the fiber before and after the $\gamma$-ray irradiation of the total dose of 3570 Gy were measured by the fiber index profiler (Interfiber Analysis, Sharon, MA, USA, IFA-100) as shown in Figure 4 . Before the $\gamma$-ray irradiation, the refractive index $\left(\Delta \mathrm{n}_{\text {cladding-core }}=0.0015\right.$, with the standard deviation of $1.05 \times 10^{-4}$ ) of the cladding larger than that of the core was due to the presence of $\mathrm{GeO}_{2}[73,74]$. The residual stress of the core was found to be under a tension of $7.7 \mathrm{MPa}$, with the standard deviation of $1.5 \mathrm{MPa}$ except the center of the core $17.5 \mathrm{MPa}$, but that of the cladding was a compression of $-26 \mathrm{MPa}$. The stress in the core is normally positive (tensile) due to the external pulling force during the drawing process. However, the compressive stress in the cladding is developed for the balance of the forces after removing the drawing tension [75,76]. On the other hand, after the $\gamma$-ray irradiation at the total dose of $3570 \mathrm{~Gy}$, no influence on the refractive index was observed. However, a change in the residual stress of the center of the core and the cladding was found. The tensile stress around the center of the core was relaxed from $17.5 \mathrm{MPa}$ to $7.0 \mathrm{MPa}$ with the slight change in tensile stress of $7.8 \mathrm{MPa}$ in the outer core region (the standard deviation of $1.3 \mathrm{MPa}$ ). Further, the compressive stress in the cladding slightly increased from $-26 \mathrm{MPa}$ to $-27 \mathrm{MPa}$. 


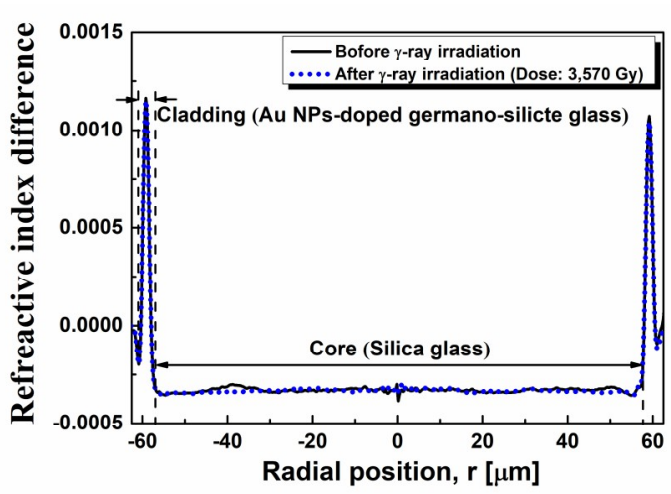

(a)

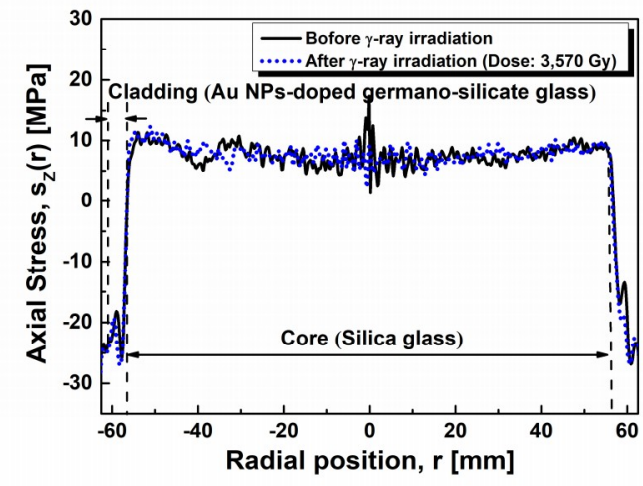

(b)

Figure 4. (a) Refractive index difference and (b) stress profile of the fiber before and after the $\gamma$-ray irradiation with the dose rate of $3570 \mathrm{~Gy}$.

To investigate the effect of the $\gamma$-ray irradiation on the SPR sensitivity, the SPR absorption of the $\mathrm{Au}$ NPs (cladding)-doped fiber was measured by dropping the index matching oils onto the stripped portions of $3 \mathrm{~cm}$. The total fiber length was $10 \mathrm{~cm}$ and the refractive index $(\mathrm{n}=1.418-1.448)$ of the matching oils was varied. Figure 5 shows the SPR spectra of the fiber before and after the irradiations of $1190 \mathrm{~Gy}, 2380 \mathrm{~Gy}$, and $3570 \mathrm{~Gy}$. Before the $\gamma$-ray irradiation, two SPR bands were found to appear, the first band around $380 \mathrm{~nm}$ and the second band around $580 \mathrm{~nm}$ [77]. The first SPR band shifted towards longer wavelength from $381.95 \mathrm{~nm}$ to $394.15 \mathrm{~nm}$ with the increase of the refractive index from 1.418 to 1.448 . The intensity of the SPR band also increased. The baseline corrected absorption intensity of the SPR spectrum from $0.80 \mathrm{~dB}$ to $4.34 \mathrm{~dB}$ increased with the increase of the refractive index due to the difference in diffraction orders [62,78]. The full width at half maximum (FWHM) of the SPR band was broadened from $49.06 \mathrm{~nm}$ to $71.29 \mathrm{~nm}$ with the increase of the refractive index due to the spatial spreading and scattering of the conduction electrons $[25,52,62,79]$. The average SPR intensity and the average FWHM were $2.09 \mathrm{~dB}$ and $60.55 \mathrm{~nm}$, respectively. However, the second SPR band wavelength $\sim 580 \mathrm{~nm}$, shown as the red dashed square in Figure 5a, was hard to define, and its appearance and the shift of the SPR band with the increase of the refractive index may be due to the low plasmon coupling of the aggregated Au NPs.

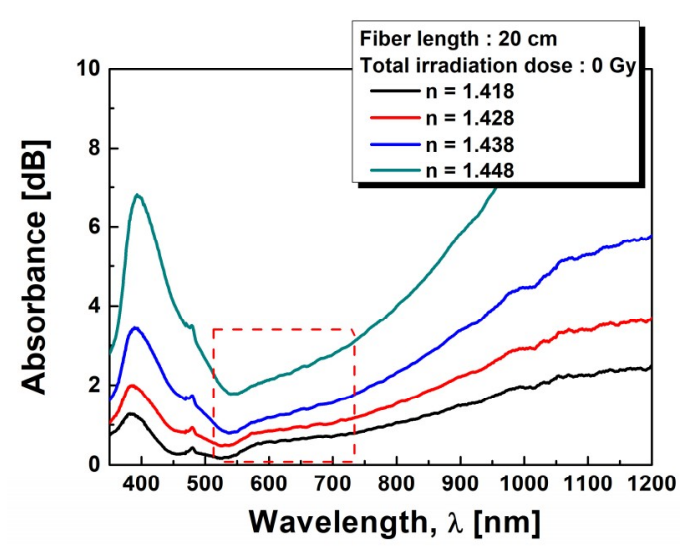

(a)

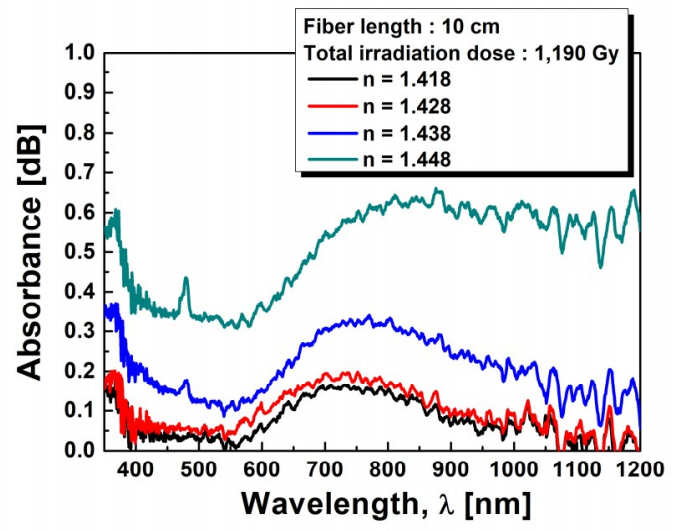

(b)

Figure 5. Cont. 


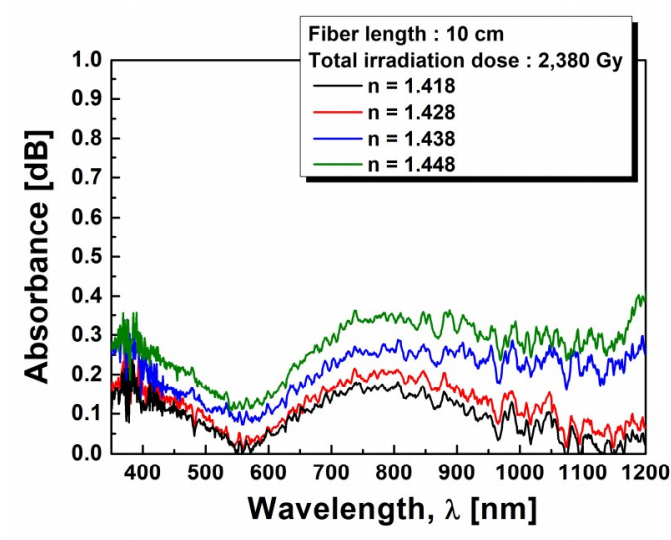

(c)

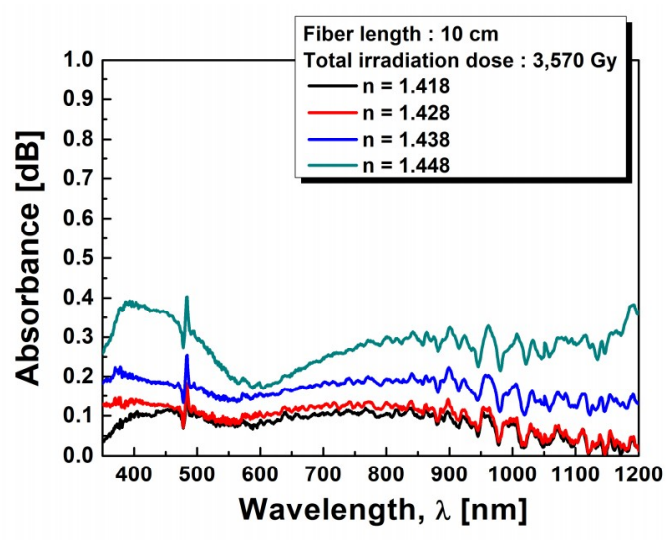

(d)

Figure 5. The SPR spectra obtained by dropping the matching oils of different refractive indices (a) before and after the $\gamma$-ray irradiation at the total dose of (b) $1190 \mathrm{~Gy}$, (c) $2380 \mathrm{~Gy}$, and (d) $3570 \mathrm{~Gy}$.

After the $\gamma$-ray irradiation, interestingly, another SPR band was found to appear around $750 \mathrm{~nm}$. The intensity of this band increased with the increase of the index. However, after the $\gamma$-ray irradiation of $1190 \mathrm{~Gy}$, the SPR band wavelength at $380 \mathrm{~nm}$ shifted towards shorter wavelength of $360 \mathrm{~nm}$. Furthermore, at the higher radiation doses, it was hard to analyze the SPR bands at short wavelengths because the SPR band intensity decreased with the increase of the optical loss and noise. The SPR band wavelength at $360 \mathrm{~nm}$ slightly shifted towards longer wavelength with the increase of the refractive index. The amount of red shift of the SPR band around $750 \mathrm{~nm}$ with the increase of the refractive index was much larger than that of the SPR band at $360 \mathrm{~nm}$ and it was due to the interparticle plasmon coupling of the aggregated Au NPs compared to the single Au NPs of the $360 \mathrm{~nm}$ band. A more detailed description is given in the discussion section.

\section{Discussion}

From the results of TEM images and size distributions of Au NPs in the cladding of the fiber before the $\gamma$-ray irradiation as shown in Figure 2a, the surface density and volume density of the Au NPs in the cladding of the fiber were estimated to be about $23 \times 10^{3} \mathrm{NPs} / \mu \mathrm{m}^{2}$ and $2,406 \times 10^{3} \mathrm{NPs} / \mu \mathrm{m}^{3}$, respectively, with the aspect ratio of 1.00 . As the total dose of the irradiation increased to $1190 \mathrm{~Gy}$, $2380 \mathrm{~Gy}$, and $3570 \mathrm{~Gy}$, the average aspect ratio of the Au NPs increased to 1.05, 1.29, and 2.00, respectively. The size distribution of the short axis of the Au NPs also slightly increased with the increase of the $\gamma$-ray irradiation level. It is clear that the $\gamma$-ray irradiation induced the growth of $A u$ NPs by the direct coalescence and consequent transformation from spherical to prolate in shape. The similar growth of crystalline Au NPs in silica glass due to Ostwald ripening by the ion irradiation was also reported [53].

Due to the morphological change of Au NPs in the fiber cladding after $\gamma$-ray irradiation, the intensity and the peak wavelength of the two SPR bands were found to change as shown in Figure 3. Before the irradiation, the separated SPR bands at $392 \mathrm{~nm}$ and $509 \mathrm{~nm}$ are due to the split of the plasmon resonance into a longitudinal SPR mode and a transverse SPR mode, parallel and perpendicular to the long axis of the Au NPs, respectively $[80,81]$. The short wavelength band at $392 \mathrm{~nm}$ is attributed to the transverse mode of SPR, which is assigned to the dipole resonance of the Au NPs. And it is much stronger than that at $509 \mathrm{~nm}$, which is attributed to the longitudinal mode of SPR, due to the spherical Au NPs. The weaker absorption at $509 \mathrm{~nm}$ from the longitudinal mode of SPR may have some contribution from the interparticle plasmon coupling of the aggregated Au NPs. After the $\gamma$-ray irradiation, the clear appearance of the SPR bands indicates the significant morphological change of the Au NPs as shown in Figure 2. With the increase of the total dose of $\gamma$-ray irradiation, the longitudinal resonance at longer wavelength of $509 \mathrm{~nm}$ seems to be dominant. It shifted from 
$509 \mathrm{~nm}$ to $553 \mathrm{~nm}, 584 \mathrm{~nm}$, and $597 \mathrm{~nm}$ with the increase of the total dose to $1190 \mathrm{~Gy}, 2380 \mathrm{~Gy}$, and $3570 \mathrm{~Gy}$, respectively. In addition, the absorption intensity increase with the increase of the total dose of $\gamma$-ray irradiation is thought to be due to the increase of the aggregated Au NPs.

The unclear peak position of the first SPR band at $392 \mathrm{~nm}$ after the $\gamma$-ray irradiation may be due to the wavelength overlap from the absorptions of the radiation-induced defects. The absorption increase may be due to the radiation-induced defects. The possible defects are oxygen deficient centers $(\mathrm{Si}-\mathrm{ODC}, \equiv \mathrm{Si}-\mathrm{Si} \equiv$ at $394 \mathrm{~nm}$ ), per-oxy radicals $(\mathrm{Si}-\mathrm{POR}, \equiv \mathrm{Si}-\mathrm{O}-\mathrm{O}$ at $630 \mathrm{~nm})$, self-trapped hole defects (Si-STHs at $477 \mathrm{~nm}, 574 \mathrm{~nm}, 663 \mathrm{~nm}, 765 \mathrm{~nm}$ ), non-bridging oxygen hole centers (Si-NBOHC, $\equiv$ Si-O-at $620 \mathrm{~nm}$ ) due to strained Si-O bonds, GeX (at $475 \mathrm{~nm}$ ), and Ge-NBOHC ( $\equiv \mathrm{Ge}-\mathrm{O}$ at $630 \mathrm{~nm}$ ) due to strained Ge-O bonds [73,82-87].

Furthermore, the splitting of the SPR bands became more distinct with the increase of $\gamma$-ray irradiation dose. It is known that the anisotropically shaped metal particles show a split SPR band due to the transverse and longitudinal modes of charge density oscillations in the presence of electromagnetic radiation $[10,11,53]$. Thus, the splitting of the SPR bands may be due to the morphological change, especially the increase of the aspect ratio, of the Au NPs. As the total dose of $\gamma$-ray irradiation increased, the longitudinal SPR band at longer wavelength of $509 \mathrm{~nm}$ showed a tendency to shift towards longer wavelength due to the growth of Au NPs from spherical to prolate in shape as shown in Figure 3b [12,81].

In the case of the refractive index and the residual stress of the fiber, after the $\gamma$-ray irradiation at the total dose of $3570 \mathrm{~Gy}$, the negligible change in the refractive index and the residual stress of the cladding by the $\gamma$-ray irradiation of the total dose of 3570 Gy does not contribute to the SPR sensing property.

From the results of the SPR sensing test by dropping the index matching oils onto the stripped portions of $3 \mathrm{~cm}$ as shown in Figure 5, the measured two SPR bands are related to the spherical Au NPs (transverse SPR mode) and the aggregated Au NPs (longitudinal SPR mode), respectively as known from the results shown in Figures 2 and 3. Before the $\gamma$-ray irradiation, the SPR sensitivity (wavelength/refractive index unit, $\mathrm{nm} / \mathrm{RIU}$ ) of the first SPR band around $380 \mathrm{~nm}$ was estimated to be $406.7 \mathrm{~nm} / \mathrm{RIU}$. It is well known that the SPR band wavelength increase with the increase of the refractive index is related to the resonance wavelength of the incident light due to the increase of the wave vector of the surface plasmon mode $[52,60-62,64,70]$. After the $\gamma$-ray irradiation, the new SPR band around $750 \mathrm{~nm}$ may be due to the interparticle plasmon coupling of the aggregated Au NP, in good agreement with the TEM results as shown in Figure 2. The Au NPs was grown in size and morphologically changed to aggregates due to the bridge-like connection and crosslinking of the $\mathrm{Au}$ NPs by the $\gamma$-ray irradiation. However, the SPR band wavelength due to the spherical Au NPs blue-shifted form $380 \mathrm{~nm}$ to $360 \mathrm{~nm}$ because the shifts of the transverse and longitudinal SPR band are contra-directed [12,81].

Finally, the results of the SPR spectra shown in Figure 5 were replotted in Figure 6 for a better look and summary. The variation of the SPR band wavelength, the SPR sensitivity, the SPR intensity, and the FWHM of the SPR spectrum were shown as a function of refractive index of the matching oils under the $\gamma$-ray irradiation. The SPR band wavelength showed a tendency to shift towards longer wavelength with the increase of the total dose of $\gamma$-ray irradiation regardless of the corresponding refractive indices due to the growth and assembly of Au NPs into the Au NP clusters by the $\gamma$-ray irradiation (Figure 6a). From the results of the SPR spectra as shown in Figure 6a, the center wavelengths of the SPR band were found at $720.67 \mathrm{~nm}, 731.33 \mathrm{~nm}, 752.29 \mathrm{~nm}$, and $827.27 \mathrm{~nm}$ with the increase of the refractive index 1.418, 1.428, 1.438, and 1.448 under at dose of $1190 \mathrm{~Gy}$, respectively. And under the total dose of $2380 \mathrm{~Gy}$ and $3570 \mathrm{~Gy}$, the SPR band wavelengths were found to appear at $760.75 \mathrm{~nm}, 781.71 \mathrm{~nm}$, $794.77 \mathrm{~nm}$, and $805.25 \mathrm{~nm}$ and at $771.53 \mathrm{~nm}, 786.70 \mathrm{~nm}, 808.65 \mathrm{~nm}$, and $841.57 \mathrm{~nm}$ with the increase of the refractive index, respectively. The estimated sensitivities (wavelength/RIU) of the SPR sensor based on the $\gamma$-ray irradiated fibers on the sensing capability of refractive index $(n=1.418-1.448)$ 
increased to be $407 \mathrm{~nm} / \mathrm{RIU}, 3553 \mathrm{~nm} / \mathrm{RIU}, 1483 \mathrm{~nm} / \mathrm{RIU}$, and $2335 \mathrm{~nm} / \mathrm{RIU}$ before and after the $\gamma$-ray irradiation at the total dose of $1190 \mathrm{~Gy}, 2380 \mathrm{~Gy}$, and $3570 \mathrm{~Gy}$, respectively, as shown in Figure $6 \mathrm{~b}$.

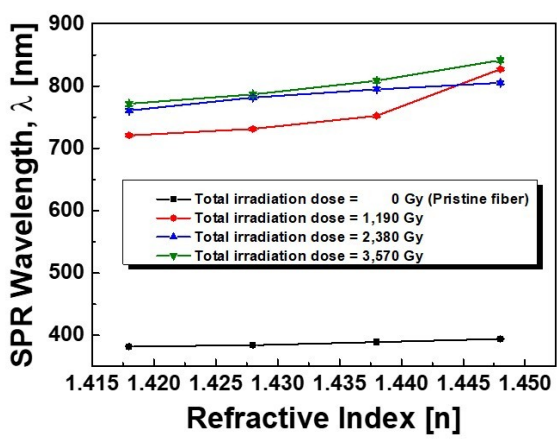

(a)

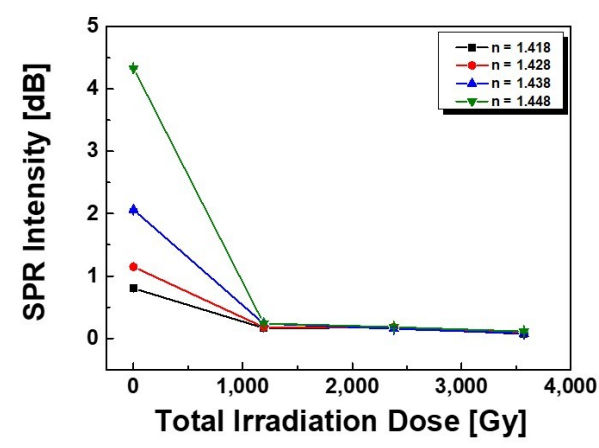

(c)

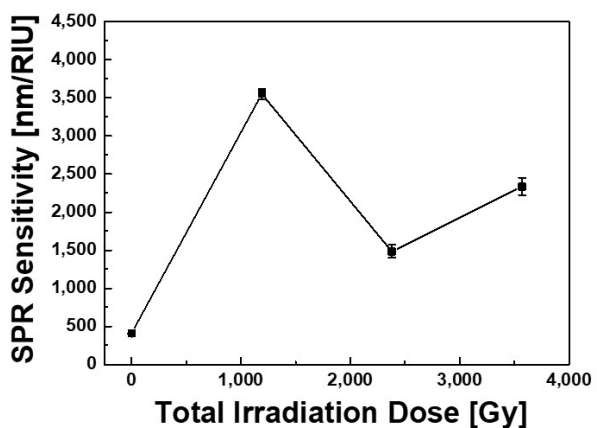

(b)

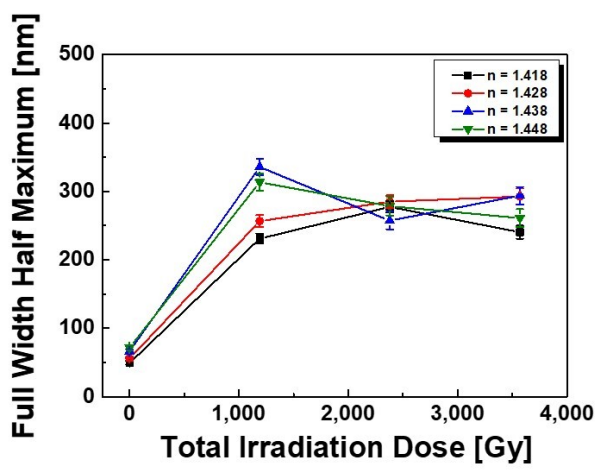

(d)

Figure 6. Variation of (a) the SPR wavelength, (b) the SPR sensitivity, (c) the SPR intensity, and (d) the FWHM of the SPR spectrum as a function of refractive index of the matching oils before and after the $\gamma$-ray irradiation at the total dose of $1190 \mathrm{~Gy}, 2380 \mathrm{~Gy}$, and $3570 \mathrm{~Gy}$.

After the $\gamma$-ray irradiation, the SPR sensitivity increased rapidly but saturated with the increase of the total dose of $\gamma$-ray irradiation. The baseline corrected SPR band intensity slightly increased from $0.17 \mathrm{~dB}$ to $0.24 \mathrm{~dB}$, from $0.17 \mathrm{~dB}$ to $0.18 \mathrm{~dB}$, and from $0.07 \mathrm{~dB}$ to $0.11 \mathrm{~dB}$ with the increase of the refractive index from 1.418 to 1.448 at the total dose of $1190 \mathrm{~Gy}, 2380 \mathrm{~Gy}$, and $3570 \mathrm{~Gy}$, respectively. The increase of the SPR intensity with the increase of the refractive indices, regardless of the $\gamma$-ray irradiation, is due to a leak of more divergent light beams from the cladding of the fiber $[5,9,88]$. However, as the total dose of $\gamma$-ray irradiation increased from 1190 Gy to 3570 Gy, the SPR band intensity decreased regardless of the corresponding refractive indices due to the increase of the radiation-induced loss as shown in Figure 6c. And the FWHM of the SPR band became broadened from $230.93 \mathrm{~nm}$ to $313.49 \mathrm{~nm}$, from $277.47 \mathrm{~nm}$ to $278.52 \mathrm{~nm}$, and from $240.48 \mathrm{~nm}$ to $260.96 \mathrm{~nm}$ with the increase of the refractive index from 1.418 to 1.448 at the total dose of $1190 \mathrm{~Gy}, 2380 \mathrm{~Gy}$, and $3570 \mathrm{~Gy}$, respectively. The broadened SPR band with the increase of the refractive indices regardless of the $\gamma$-ray irradiation is due to the spatial spreading and scattering of the conduction electrons and the FWHM of the SPR band was saturated with the increase of the total dose of $\gamma$-ray irradiation as shown in Figure 6d [25,62,79]. Note that the center wavelength, intensity, and the FWHM of the SPR band were rapidly changed after the $\gamma$-ray irradiation at the total dose of $1190 \mathrm{~Gy}$ as compared with the fiber before the $\gamma$-ray irradiation. However, the change in center wavelength, intensity, and the FWHM of the SPR band was saturated as the total dose of $\gamma$-ray irradiation of $2380 \mathrm{~Gy}$ and $3570 \mathrm{~Gy}$ increased regardless of the corresponding refractive indices.

The SPR sensitivity, the average intensity, and the average FWHM of the fiber before and after the $\gamma$-ray irradiation at the total dose of $1190 \mathrm{~Gy}, 2380 \mathrm{~Gy}$, and $3570 \mathrm{~Gy}$ are listed in Table 1. The average intensity and the FWHM were changed from $0.20 \mathrm{~dB}$ to $0.17 \mathrm{~dB}$ and $0.08 \mathrm{~dB}$ and from $284.21 \mathrm{~nm}$ to 
$274.59 \mathrm{~nm}$ and $272.03 \mathrm{~nm}$ at the total dose of $1190 \mathrm{~Gy}, 2380 \mathrm{~Gy}$, and $3570 \mathrm{~Gy}$, respectively. The average intensity and the FWHM of the SPR band around $750 \mathrm{~nm}$ in the range of the refractive index from 1.418 to 1.448 decreased with the increase of the total dose of $\gamma$-ray irradiation at $1190 \mathrm{~Gy}, 2380 \mathrm{~Gy}$, and $3570 \mathrm{~Gy}$.

Table 1. The SPR sensitivity, the average intensity, and the average FWHM of the optical fiber embedded with Au NPs in cladding after the $\gamma$-ray irradiation.

\begin{tabular}{ccccc}
\hline $\boldsymbol{\gamma}$-ray Irradiation & $\begin{array}{c}\text { Total } \boldsymbol{\gamma} \text {-ray } \\
\text { Irradiation Dose } \\
{[\text { [Gy] }}\end{array}$ & $\begin{array}{c}\text { Sensitivity } \\
{[\mathbf{n m} / \mathbf{R I U}]}\end{array}$ & $\begin{array}{c}\text { Average Intensity } \\
{[\mathbf{d B}]}\end{array}$ & $\begin{array}{c}\text { Average FWHM } \\
\text { [nm] }\end{array}$ \\
\hline Before & 0 & 407 & 2.087 & 60.554 \\
$(\mathrm{SPR}$ at 380 $\mathrm{nm})$ & 1190 & 3553 & 0.204 & 284.207 \\
After & 2380 & 1483 & 0.170 & 274.592 \\
$(\mathrm{SPR}$ at 750 $\mathrm{nm})$ & 3570 & 2335 & 0.084 & 272.026 \\
\hline
\end{tabular}

From the SPR results of the fibers after the $\gamma$-ray irradiation, the growth of the Au NPs to anisotropically shaped Au clusters must have played an important role because it showed the splitting of the SPR band into the transverse and longitudinal modes $[10,11,53]$. The increase in the aspect ratio of the Au cluster led to red shifts of the longitudinal SPR band (longer wavelength) and it showed better sensitivity in response to changes in refractive index of the surrounding medium because the refractive index sensitivity of the SPR sensor was enhanced with increasing SPR band wavelength [89]. However, an excessive $\gamma$-ray irradiation is detrimental due to the decrease of the SPR sensitivity and the increase of the radiation-induced optical loss by excessively changing the size and shape of $\mathrm{Au}$ NPs. Nevertheless, the $\gamma$-ray irradiation of the SPR sensor fiber with an appropriate irradiation dose is an effective method to increase the SPR sensitivity and to control a desired detection wavelength for utilizing a commercially available light source and power detector.

\section{Conclusions}

The silica glass optical fiber incorporated with Au NPs in the germano-silicate glass cladding has been irradiated by ${ }^{60} \mathrm{Co} \gamma$-rays with the dose rate of $1190 \mathrm{~Gy} / \mathrm{h}$ for $1 \mathrm{~h}$ to $3 \mathrm{~h}$ at room temperature to investigate the enhancement of the SPR sensitivity and the enabling tunability of the operation range of sensing wavelength of the SPR for the refractive index sensing by controlling the size and shape of the incorporated crystalline Au NPs in the fiber cladding. As the total dose of the $\gamma$-ray irradiation increased to $1190 \mathrm{~Gy}, 2380 \mathrm{~Gy}$ and $3570 \mathrm{~Gy}$, the average aspect ratio of the Au NPs increased from 1.0 to $1.05,1.29$, and 2.00, respectively. The spherical Au NPs of $\sim 3.8 \mathrm{~nm}$ diameter grew into the large clusters by the direct coalescence of NPs and then transformed to prolate shaped particles with a large aspect ratio.

The anisotropically grown Au NPs with a large aspect ratio were the main cause of the splitting of the SPR bands into transverse and longitudinal modes, and this splitting became more distinct with the increase of $\gamma$-ray irradiation dose. Due to the effective shift and the intensity increase of the longitudinal SPR band at the longer wavelength of $509 \mathrm{~nm}$ after the $\gamma$-ray irradiation, the SPR sensitivity for the corresponding refractive indices $(n=1.418-1.448)$ increased rapidly but saturated from $406.7 \mathrm{~nm} /$ RIU to $3553 \mathrm{~nm} /$ RIU, $1483 \mathrm{~nm} /$ RIU, and $2335 \mathrm{~nm} /$ RIU with the increase of the total dose of $\gamma$-ray irradiation from 0 Gy to $1190 \mathrm{~Gy}, 2380 \mathrm{~Gy}$, and $3570 \mathrm{~Gy}$, respectively. However, the average SPR intensity decreased from $0.20 \mathrm{~dB}$ to $0.17 \mathrm{~dB}$ and $0.08 \mathrm{~dB}$ and the average FWHM of the SPR band around $750 \mathrm{~nm}$ also decreased from $284.21 \mathrm{~nm}$ to $274.59 \mathrm{~nm}$ and $272.03 \mathrm{~nm}$ with the increase of the total dose from $1190 \mathrm{~Gy}$ to $2380 \mathrm{~Gy}$, and $3570 \mathrm{~Gy}$, respectively. On the other hand, the transverse SPR band at $392 \mathrm{~nm}$ has not shown any significant increase in its intensity and wavelength shift. However, from the SPR sensing experiment using refractive index-matching oils after the $\gamma$-ray irradiation of $1190 \mathrm{~Gy}$, the transverse SPR band at $380 \mathrm{~nm}$ was found to shift to $360 \mathrm{~nm}$. 
No significant change in the refractive index and the residual stress after the $\gamma$-ray irradiation at the total dose of $3570 \mathrm{~Gy}$ indicates no contribution of them to the SPR sensing capability.

Author Contributions: S.J. conceived of the study, participated in the design of the experiments, performed the analysis, and wrote the paper; W.-T.H. conceived of the study and coordination and helped to draft the manuscript.

Funding: This research was partially funded by the KEPCO Research Institute of South Korea under the grant number KEPRI-16-23.

Acknowledgments: This work was supported by the Advanced Technology Radiation Laboratory of the Korea Atomic Energy Research Institute, South Korea.

Conflicts of Interest: The authors declare no conflict of interest.

\section{References}

1. Homola, J.; Yee, S.S.; Gauglitz, G. Surface plasmon resonance sensors: Review. Sens. Actuators B 1999, 54, 3-15. [CrossRef]

2. Yonzon, C.R.; Jeoung, E.; Zou, S.; Schatz, G.C.; Mrksich, M.; Duyne, R.P.V. A comparative analysis of localized and propagating surface plasmon resonance sensors: The binding of concanavalin A to a monosaccharide functionalized self-assembled monolayer. J. Am. Chem. Soc. 2004, 126, 12669-12676. [CrossRef] [PubMed]

3. Nath, N.; Chilkoti, A. Label-free biosensing by surface plasmon resonance of nanoparticles on glass: Optimization of nanoparticle size. Anal. Chem. 2004, 76, 5370-5378. [CrossRef]

4. Yu, F.; Ahl, S.; Caminade, A.-M.; Majoral, J.-P.; Knoll, W.; Erlebacher, J. Simultaneous excitation of propagating and localized surface plasmon resonance in nanoporous gold membranes. Anal. Chem. 2006, 78, 7346-7350. [CrossRef] [PubMed]

5. Garcia, M.A. Corrigendum: Surface plasmons in metallic nanoparticles: Fundamentals and applications. J. Phys. D Appl. Phys. 2012, 45, 389501. [CrossRef]

6. Peng, T.-C.; Lin, W.-C.; Chen, C.-W.; Tsai, D.P.; Chiang, H.-P. Enhanced sensitivity of surface plasmon resonance phase-interrogation biosensor by using silver nanoparticles. Plasmonics 2011, 6, 29-34. [CrossRef]

7. Lee, K.-S.; El-Sayed, M.A. Gold and silver nanoparticles in sensing and imaging: Sensitivity of plasmon response to size, shape, and metal composition. J. Phys. Chem. B 2006, 110, 19220-19225. [CrossRef]

8. Sönnichsen, C.; Reinhard, B.M.; Liphardt, J.; Alivisatos, A.P. A molecular ruler based on plasmon coupling of single gold and silver nanoparticles. Nat. Biotechnol. 2005, 23, 741-745.

9. Luther, J.M.; Jain, P.K.; Ewers, T.; Alivisatos, A.P. Localized surface plasmon resonances arising from free carriers in doped quantum dots. Nat. Mater. 2011, 10, 361-366. [CrossRef]

10. Mohamed, M.B.; Volkov, V.; Link, S.; El-Sayed, M.A. The 'lighting' gold nanorods: Fluorescence enhancement of over a million compared to the gold metal. Chem. Phys. Lett. 2000, 317, 517-523. [CrossRef]

11. Jiang, Z.; Wen, G.; Luo, Y.; Zhang, X.; Liu, Q.; Liang, A. A new silver nanorod SPR probe for detection of trace benzoyl peroxide. Sci. Rep. 2014, 4, 5323. [CrossRef]

12. Link, S.; El-Sayed, M.A. Optical properties and ultrafast dynamics of metallic nanocrystals. Annu. Rev. Phys. Chem. 2003, 54, 331-366. [CrossRef]

13. Dawi, E.A.; Rizza, G.; Mink, M.P.; Vredenderg, A.M.; Habraken, F.H.P.M. Ion beam shaping of Au nanoparticles in silica: Particle size and concentration dependence. J. Appl. Phys. 2009, 105, 074305. [CrossRef]

14. Kabashin, A.V.; Evans, P.; Pastkovsky, S.; Hendren, W.; Wurtz, G.A.; Atkinson, R.; Pollard, R.; Podolskiy, V.A.; Zayats, A.V. Plasmonic nanorod metamaterials for biosensing. Nat. Mater. 2009, 8, 867-871. [CrossRef]

15. Singh, S.; Gupta, B.D. Simulation of a surface plasmon resonance-based fiber-optic sensor for gas sensing in visible range using films of nanocomposites. Meas. Sci. Technol. 2010, 21, 115202. [CrossRef]

16. Jorgenson, R.C.; Yee, S.S. A fiber-optic chemical sensor based on surface plasmon resonance. Sens. Actuators B Chem. 1993, 12, 213-220. [CrossRef]

17. Matsubara, K.; Kawata, S.; Minami, S. Optical chemical sensor based on surface plasmon measurement. Appl. Opt. 1998, 27, 1160-1163. [CrossRef]

18. Liedberg, B.; Nylander, C.; Lunström, I. Surface plasmon resonance for gas detection and biosensing. Sens. Actuators 1983, 4, 299-304. [CrossRef] 
19. Sharma, S.K.; Gupta, B.D. Simulation of a localized surface-plasmon-resonance-based fiber optic temperature sensor. Opt. Soc. Am. A 2010, 27, 1743-1749.

20. Homola, J. Present and future of surface plasmon resonance biosensors. Anal. Bioanal. Chem. 2003, 377, 528-539. [CrossRef]

21. Haes, A.J.; Hall, W.P.; Chang, L.; Klein, W.L.; Van Duyne, R.P. A localized surface plasmon resonance biosensor: First steps toward an assay for Alzheimer's disease. NANO Lett. 2004, 4, 1029-1034. [CrossRef]

22. Lin, Y.; Zou, Y.; Lindquist, R.G. A reflection-based localized surface plasmon resonance fiber-optic probe for biochemical sensing. Biomed. Opt. Express 2011, 2, 478-484. [CrossRef]

23. Anker, J.N.; Hall, W.P.; Lyandres, O.; Shan, N.C.; Zhao, J.; Duyne, R.P.V. Biosensing with plasmonic nanosensors. Nat. Mater. 2008, 7, 442-453. [CrossRef]

24. Chung, P.-Y.; Lin, T.-H.; Schultz, G.; Batich, C.; Jiang, P. Nanopyramid surface plasmon resonance sensors. Appl. Phys. Lett. 2010, 96, 261108. [CrossRef]

25. Zhang, Y.; Yuwono, A.H.; Li, J.; Wang, J. Highly dispersed gold nanoparticles assembled in mesoporous titania films of cubic configuration. Microporous Mesoporous Mater. 2008, 110, 242-249. [CrossRef]

26. Jensen, T.R.; Schatz, G.C.; Van Duyne, R.P. Nanosphere lithography: Surface plasmon resonance spectrum of a periodic array of silver nanoparticles by ultraviolet-visible extinction spectroscopy and electrodynamic modeling. J. Phys. Chem. B 1999, 103, 2394-2401. [CrossRef]

27. Chang, S.H.; Gray, S.K.; Schatz, G.C. Surface plasmon generation and light transmission by isolated nanoholes and arrays of nanoholes in thin metal films. Opt. Express 2005, 13, 3150-3165. [CrossRef]

28. Aizpurua, J.; Hanarp, P.; Sutherland, D.S.; Kall, M.; Bryant, G.W.; de Abajo, F.J.G. Optical properties of gold nanorings. Phys. Rev. Lett. 2003, 90, 057401. [CrossRef]

29. Fu, J.; Park, B.; Zhao, Y. Nanorod-mediated surface plasmon resonance sensor based on effective medium theory. App. Opt. 2009, 48, 4637-4649. [CrossRef]

30. Kim, J.; Liu, G.L.; Lu, Y.; Lee, L.P. Spectral tuning of localised surface plasmon-polariton resonance in metallic nano-crescents. IEE Proc.-Nanobiotechnol. 2006, 153, 42-46. [CrossRef]

31. Liu, Z.W.; Wei, Q.H.; Zhang, X. Surface plasmon interference nanolithography. Nano. Lett. 2005, 5, $957-961$. [CrossRef]

32. Halas, N. Playing with plasmons: Tuning the optical resonant properties of metallic nanoshells. MRS Bull. 2005, 30, 362-367. [CrossRef]

33. Khlebtsov, N.G. Optics and biophotonics of nanoparticles with a plasmon resonance. Quantum Electron. 2008, 38, 504-529. [CrossRef]

34. Takahata, R.; Yamazoe, S.; Koyasu, K.; Tsukuda, T. Surface plasmon resonance in gold ultrathin nanorods and nanowires. J. Am. Chem. Soc. 2014, 136, 8489-8491. [CrossRef]

35. Zhang, Q.; Hu, Y.; Guo, S.; Goebl, J.; Yin, Y. Seeded growth of uniform Ag nanoplates with high aspect ratio and widely tunable surface plasmon bands. Nano Lett. 2010, 10, 5037-5042. [CrossRef]

36. Zhu, J.; Deng, X.-C. Improve the refractive index sensitivity of gold nanotube by reducing the restoring force of localized surface plasmon resonance. Sens. Actuators B Chem. 2011, 155, 843-847. [CrossRef]

37. Mahmoud, M.A.; El-Sayed, M.A. Time dependence and signs of the shift of the surface plasmon resonance frequency in nanocages elucidate the nanocatalysis mechanism in hollow nanoparticles. Nano Lett. 2011, 11, 946-953. [CrossRef]

38. Ringe, E.; McMahon, J.M.; Sohn, K.; Cobley, C.; Xia, Y.; Huang, J.; Schatz, G.C.; Marks, L.D.; Van Duyne, R.P. Unraveling the effects of size, composition, and substrate on the localized surface plasmon resonance frequencies of gold and silver nanocubes: A systematic single-particle approach. J. Phys. Chem. C 2010, 114, 12511-12516. [CrossRef]

39. Zeng, S.; Yu, X.; Law, W.-C.; Zhang, Y.; Hu, R.; Dinh, X.-Q.; Ho, H.-P.; Yong, K.-T. Size dependence of Au NP-enhanced surface plasmon resonance based on differential phase measurement. Sensor. Actuat. B Chem. 2013, 176, 1128-1133. [CrossRef]

40. Kwon, M.J.; Lee, J.; Wark, A.W.; Lee, H.J. Nanoparticle-enhanced surface plasmon resonance detection of proteins at Attomolarc: Comparing different nanoparticle shapes and sizes. Anal. Chem. 2012, 84, 1702-1707. [CrossRef]

41. Chen, C.-D.; Cheng, S.-F.; Chau, L.-K.; Wang, C.R.C. Sensing capability of the localized surface plasmon resonance of gold nanorods. Biosens. Bioelectron. 2007, 22, 926-932. [CrossRef] 
42. Muskens, O.L.; Bachelier, G.; Fatti, N.D.; Vallée, F.; Brioude, A.; Jiang, X.; Pileni, M.-P. Quantitative absorption spectroscopy of a single gold nanorod. J. Phys. Chem. C 2008, 112, 8917-8921. [CrossRef]

43. Mallick, K.; Wang, Z.L.; Pal, T. Seed-mediated successive growth of gold particles accomplished by UV irradiation: A photochemical approach for size-controlled synthesis. J. Photochem. Photobiol. A Chem. 2001, 140, 75-80. [CrossRef]

44. Stamplecoskie, K.G.; Scaiano, J.C. Light emitting diode irradiation can control the morphology and optical properties of silver nanoparticles. J. Am. Chem. Soc. 2010, 132, 1825-1827. [CrossRef]

45. Stellacci, F.; Bauer, C.A.; Meyer-Friedrichsen, T.; Wenseleers, W.; Alain, V.; Kuebler, S.M.; Pond, S.J.K.; Zhang, Y.; Marder, S.R.; Perry, J.W. Laser and electron-beam induced growth of nanoparticles for 2D and 3D metal patterning. Adv. Mater. 2002, 14, 194-198. [CrossRef]

46. Abid, J.P.; Wark, A.W.; Brevet, P.F.; Girault, H.H. Preparation of silver nanoparticles in solution from a silver salt by laser irradiation. Chem. Commun. 2002, 7, 792-793. [CrossRef]

47. Mishra, Y.K.; Avasthi, D.K.; Kulriya, P.K.; Singh, F.; Kabiraj, D.; Tripathi, A.; Pivin, J.C.; Bayer, I.S.; Biswas, A. Controlled growth of gold nanoparticles induced by ion irradiation: An in situ x-ray diffraction study. Appl. Phys. Lett. 2007, 91, 073110. [CrossRef]

48. Valentin, E.; Bernas, H.; Ricolleau, C.; Creuzet, F. Ion Beam "Photography": Decoupling nucleation and growth of metal clusters in glass. Phys. Rev. Lett. 2001, 86, 99-102. [CrossRef]

49. Chen, P.; Song, L.; Liu, Y.; Fang, Y. Synthesis of silver nanoparticles by $\gamma$-ray irradiation in acetic water solution containing chitosan. Radiat. Phys. Chem. 2007, 76, 1165-1168. [CrossRef]

50. Yokan, R.; Chirachanchai, S. Silver nanoparticles dispersing in chitosan solution: Preparation by $\gamma$-ray irradiation and their antimicrobial activities. Mater. Chem. Phys. 2009, 115, 296-302. [CrossRef]

51. Ju, S.; Watekar, P.R.; Kim, C.; Han, W.-T. Particle size control of PbTe quantum dots incorporated in the germano-silicate glass optical fiber by heat treatment. J. Non-Cryst. Solids 2010, 356, 2273-2276. [CrossRef]

52. Ju, S.; Jeong, S.; Kim, Y.; Lee, S.-H.; Linganna, K.; Kim, C.J.; Han, W.-T. Effect of heat treatment of optical fiber incorporated with Au nano-particles on surface plasmon resonance. Opt. Mater. Express 2015, 5, 1440-1449. [CrossRef]

53. Mishra, Y.K.; Singh, F.; Pivin, J.C.; Malinovska, D.; Pippel, E.; Avasthi, D.K. Synthesis of elongated Au nanoparticles in silica matrix by ion irradiation. Appl. Phys. Lett. 2007, 91, 063103. [CrossRef]

54. D'Orléans, C.; Stoquert, J.P.; Estournès, C.; Cerruti, C.; Grob, J.J.; Guille, J.L.; Haas, F.; Muller, D.; Richard-Plouet, M. Anisotropy of Co nanoparticles induced by swift heavy ions. Phys. Rev. B 2003, 67, 220101. [CrossRef]

55. Daniel, M.-C.; Astruc, D. Gold nanoparticles: Assembly, supramolecular chemistry, quantum-size-related properties, and applications toward biology, catalysis, and nanotechnology. Chem. Rev. 2004, 104, 93-346. [CrossRef]

56. Bringa, E.M.; Johnson, R.E. Coulomb explosion and thermal spikes. Phys. Rev. Lett. 2002, 88, 165501. [CrossRef]

57. Joseph, B.; Ghatak, J.; Lenka, H.P.; Kuiri, P.K.; Sahu, G.; Mishra, N.C.; Mahapatra, D.P. Effect of $100 \mathrm{MeV} \mathrm{Au}$ irradiation on embedded Au nanoclusters in silica glass. Nucl. Instr. Meth. Phys. Res. B 2007, 256, 659-664. [CrossRef]

58. Slavík, R.; Homola, J.; Čtyroký, J.; Brynda, E. Novel spectral fiber optic sensor based on surface plasmon resonance. Sens. Actuators B Chem. 2001, 74, 106-111. [CrossRef]

59. Sharma, A.K.; Jha, R.; Gupta, B.D. Fiber-optic sensors based on surface plasmon resonance: A comprehensive review. IEEE Sens. J. 2007, 7, 1118-1129. [CrossRef]

60. Gupta, B.D.; Verma, R.K. Surface plasmon resonance-based fiber optic sensors: Principle, probe designs, and some applications. J. Sens. 2009, 2009, 1-12. [CrossRef]

61. Mitsushio, M.; Higashi, S.; Higo, M. Construction and evaluation of a gold-deposited optical fiber sensor system for measurements of refractive indices of alcohols. Sens. Actuators A Phys. 2004, 111, 252-259. [CrossRef]

62. Ju, S.; Jeong, S.; Kim, Y.; Jeon, P.; Park, M.-S.; Jeong, H.; Boo, S.; Jang, J.-H.; Han, W.-T. Experimental demonstration of surface plasmon resonance enhancement of the tapered optical fiber coated with $\mathrm{Au} / \mathrm{Ti}$ thin film. J. Non-Cryst. Solids 2013, 383, 146-152. [CrossRef]

63. Singh, S.; Verma, R.K.; Gupta, B.D. Surface plasmon resonance based fiber optic sensor with symmetric and asymmetric metallic coatings: A comparative study. Sens. Transducers J. 2009, 100, 116-124. 
64. Jeong, H.-H.; Erdene, N.; Park, J.-H.; Jeong, D.-H.; Lee, S.-K. Analysis of fiber-optic localized surface plasmon resonance sensor by controlling formation of gold nanoparticles and its bio-application. J. Nanosci. Nanotechnol. 2012, 12, 7815-7821. [CrossRef]

65. Lee, B.; Roh, S.; Park, J. Current status of micro- and nano-structured optical fiber sensors. Opt. Fiber Technol. 2009, 15, 209-221. [CrossRef]

66. Shevchenko, Y.Y.; Albert, J. Plasmon resonances in gold-coated tilted fiber Bragg grating. Opt. Lett. 2007, 32, 211-213. [CrossRef]

67. Sanders, M.; Lin, Y.; Wei, J.; Bono, T.; Lindquist, R.G. An enhanced LSPR fiber-optic nanoprobe for ultrasensitive detection of protein biomarkers. Biosens. Bioelectron. 2014, 61, 95-101. [CrossRef]

68. Caucheteur, C.; Guo, T.; Albert, J. Review of plasmonic fiber optic biochemical sensors: Improving the limit of detection. Anal. Bioanal. Chem. 2015, 407, 3883-3897. [CrossRef]

69. Cao, J.; Tu, M.H.; Sun, T.; Grattan, K.T.V. Wavelength-based localized surface plasmon resonance optical fiber biosensor. Sensor. Actuat. B Chem. 2013, 181, 611-619. [CrossRef]

70. Ju, S.; Jeong, S.; Kim, Y.; Lee, S.-H.; Han, W.-T. Surface plasmon resonance characteristics of optical fiber incorporated with Au nano-particles in cladding region. J. Nanosci. Nanotechnol. 2016, 16, 6308-6312. [CrossRef]

71. Ju, S.; Jeong, S.; Kim, Y.; Jeon, P.; Boo, S.; Han, W.-T. Development of specialty optical fiber incorporated with Au nano-particles in cladding for surface plasmon resonance sensors. Sens. Transducers J. 2013, 18, 76-83.

72. Roman, J.E.; Wincik, K.A. Photowritten gratings in ion-exchanged glass waveguides. Opt. Lett. 1993, 18, 808-810. [CrossRef]

73. Girard, S.; Kuhnhenn, J.; Gusarov, A.; Brichard, B.; Van Uffelen, M.; Ouerdane, Y.; Boukenter, A.; Marcandella, C. Radiation effects on silica-based optical fibers: Recent advances and future challenges. IEEE Trans. Nucl. Sci. 2013, 60, 2015-2036. [CrossRef]

74. Chu, P.L.; Whitbread, T. Measurement of stresses in optical fiber and preform. Appl. Opt. 1982, 21, 4241-4245. [CrossRef]

75. Kim, B.H.; Park, Y.; Ahn, T.-J.; Kim, D.Y.; Lee, B.H.; Chung, Y.; Paek, U.-C.; Han, W.-T. Residual stress relaxation in the core of optical fiber by $\mathrm{CO}_{2}$ laser irradiation. Opt. Lett. 2001, 26, 1657-1659. [CrossRef]

76. Kim, B.H.; Ahn, T.-J.; Kim, D.Y.; Lee, B.H.; Chung, Y.; Paek, U.-C.; Han, W.-T. Effect of $\mathrm{CO}_{2}$ laser irradiation on the refractive-index change in optical fibers. Appl. Opt. 2002, 41, 3809-3815. [CrossRef]

77. Chen, H.; Kou, X.; Yang, Z.; Ni, W.; Wang, J. Shape- and size-dependent refractive index sensitivity of gold nanoparticles. Langmuir 2008, 24, 5233-5237. [CrossRef]

78. Dou, X.; Phillips, B.M.; Chung, P.-Y.; Jiang, P. High surface plasmon resonance sensitivity enabled by optical disks. Opt. Lett. 2012, 37, 3681-3683. [CrossRef]

79. Lee, M.; Chae, L.; Lee, K.C. Microstructure and surface plasmon absorption of sol-gel-prepared Au nanoclusters in $\mathrm{TiO}_{2}$ thin films. NanoStruct. Mater. 1999, 11, 195-201. [CrossRef]

80. Ghosh, S.K.; Pal, T. Interparticle coupling effect on the surface plasmon resonance of Gold nanoparticles: From theory to applications. Chem. Rev. 2007, 107, 4794-4862. [CrossRef]

81. El-Brolossy, T.A.; Abdallah, T.; Mohamed, M.B.; Abdallah, S.; Easawi, K.; Negm, S.; Talaat, H. Shape and size dependence of the surface plasmon resonance of gold nanoparticles studied by photoacoustic technique. Eur. Phys. J. Spec. Top. 2008, 153, 361-364. [CrossRef]

82. Kim, Y.; Ju, S.; Jeong, S.; Lee, S.H.; Han, W.-T. Gamma-ray radiation response at $1550 \mathrm{~nm}$ of fluorine-doped radiation hard single-mode optical fiber. Opt. Express 2016, 24, 3910-3920. [CrossRef]

83. Regnier, E.; Flammer, I.; Girard, S.; Gooijer, F.; Achten, F.; Kuyt, G. Low-dose radiation-induced attenuation at infrared wavelengths for P-doped, Ge-doped and pure silica-core optical fibres. IEEE Trans. Nucl. Sci. 2007, 54, 1115-1119. [CrossRef]

84. Origlio, G.; Boukenter, A.; Girard, S.; Richard, N.; Cannas, M.; Boscaino, R.; Ouerdane, Y. Irradiation induced defects in fluorine doped silica. Nucl. Instrum. Methods Phys. Res. Sect. B 2008, 266, 2918-2922. [CrossRef]

85. Kajihara, K.; Hirano, M.; Skuja, L.; Hosono, H. ${ }^{60} \mathrm{Co} \gamma$-ray-induced intrinsic defect processes in fluorine-doped synthetic $\mathrm{SiO}_{2}$ glasses of different fluorine concentrations. Mater. Sci. Eng. B 2009, 161, 96-99. [CrossRef]

86. Giacomazzi, L.; Martin-Samos, L.; Boukenter, A.; Ouerdane, Y.; Girard, S.; Richard, N. Ge(2), Ge(1) and Ge-E' centers in irradiated Ge-doped silica: A first-principles EPR study. Opt. Mater. Express 2015, 5, 1054-1064. [CrossRef] 
87. Kyoto, M.; Chigusa, Y.; OOE, M.; Watanabe, M.; Matubara, T.; Yamamoto, T.; Okamoto, S. Gamma-ray irradiation effect on loss increase of single mode optical fibers, (I). J. Nucl. Sci. Technol. 1989, 26, 507-515. [CrossRef]

88. Yeri, A.S.; Gao, L.; Gao, D. Mutation screening based on the mechanical properties of DNA molecules tethered to a solid surface. J. Phys. Chem. B 2010, 114, 1064-1068. [CrossRef]

89. Kazuma, E.; Tatsuma, T. Localized surface plasmon resonance sensors based on wavelength-tunable spectral dips. Nanoscale 2014, 6, 2397-2405. [CrossRef]

(C) 2019 by the authors. Licensee MDPI, Basel, Switzerland. This article is an open access article distributed under the terms and conditions of the Creative Commons Attribution (CC BY) license (http:/ / creativecommons.org/licenses/by/4.0/). 